\title{
Evaluation of Analytical Results Obtained From Standard AOAC Method and Accelerated Wijs Method for the Determination of Iodine Value of Different Brands of Mustard Edible Oils
}

\author{
*Dr. Shashikant Pardeshi \\ *Food Analyst, DPHL, Jalgaon. Email
}

\begin{abstract}
In the present work, accelerated method is used for the measurement of iodine value, wherein mercuric acetate is directly used in the powder form. The method only requires to add the catalyst mercuric acetate in the process of determination without changing the operational steps of the Wijs method. Compared with the Wijs method in which it will take at least 30 minutes to finish it, the rapid determination method can make the determination reaction finished in 3 minutes. The iodine value of different vegetable oils such as Kacchighani mustard oil (Kgmu, Dalda),Kacchighani mustard oil (Kgmu1,Mahakosh), Kacchighani mustard oil (Kgmu2,Tez),premium mustard oil kacchighaani (Pmukg, RRO Mustdil), Kacchighani mustard oil (Kgmu3,Nature fresh) and Kacchighani mustard oil (Kgmu4, Engine)oils were determined by regular Wijs method for 30 minutes whereas when we apply catalytic Wijs method with use of $2 \mathrm{mg}, 5 \mathrm{mg}$ and $10 \mathrm{mg}$ of mercuric acetate to perform as catalyst then it is reducing the time of analysis to 3 minutes. When catalyst is used the different values obtained for standard deviations are 0.14 for $2 \mathrm{mg}, 0.27$ for $5 \mathrm{mg}$ and 0.3 for 10 mg whereas 0.35 for non catalyst addition. The results obtained in this present work aremore \% difference in IV of pure kacchighani mustard oil (Pkgmu)and Kacchighani mustard oil (Kgmu2).
\end{abstract}

Keywords:- IV (Iodine Value), Wijs Method, Mercuric Acetate, Vegetable Oils.

\section{INTRODUCTION}

Vegetable oils are extracted from seeds, such as soy, cotton, corn, and sunflower. They are characterized by high concentrations of triglycerides and lower amounts of mono and diglycerides, free fatty acids, tocopherols, proteins, sterols, and vitamins. Triglycerides with a high number of unsaturation predominate in most of the vegetable oils (e.g. soy, cotton, corn, mustard and sunflower oils), which makes them more susceptible to oxidation. Some refined oils, such as those extracted from sunflower, canola, and soybean are essentially intended for food preparation. On the other hand, oils are also widely demanded for biodiesel production (e.g. soybean and cotton oils), which alternatively can be produced from animal fats[10].
The quality of fats and oils is dictated by several physical such as texture, density, pacific gravity, colour, refractive index etc and chemical parameters such as acid value, iodine value, saponification value, unsaponifiable matter BTT etc are dependent on the source of oil; geographic, climatic, and agronomic variables of growth. Thus one must assess quantitatively the influence of these variables on characteristics of oils and fats.Many methods have been developed, the Wijs method is the most widely used as a standard methodin food analysis laboratories. Major drawbacks of that method include the use of dangerous iodinetrichloride (Wijs reagent) and the timeconsuming asduration of the reaction is as long as 30-60 minutes and procedures for reagent preparation and chemical analysis. Numerous efforts have been made to reduce the time by use of accelerators as mercuric acetate. In this paper mercuric acetate is used as a catalyst/accelerator to achieve a reduction in the reaction time.The official methods for determination of iodine value (IV) involve the reaction of double bonds in oils with halogenating reagent (Wijs solution) over $30 \mathrm{~min}$ followed by iodometric titration of the liberated iodine obtained through reaction of excess Wijs reagent with potassium iodide with sodium thiosulphate solution using starch as an indicator. Wijs method is generally adopted for the measurement of iodine value $[1,3]$.

Objective of this research study is to develop a method by which time of the Wijs method can be reduced by use of mercuric acetate as a catalyst/accelerator and examines the comparison between catalytic or accelerated improved method with AOAC standard Wijs method for IV analysis.

\section{LITERATURE REVIEW}

According to Jnmiat et al, various methods and modifications that have been proposed on time to time for the determination of the Iodine values of fats and oils, Hubl's and Wijs' are the only two methods which have found more or less general application [7].Hoffman and Green used mercuric acetate as a catalyst in the Wijs method to obtain complete iodine absorption in three minutes [6]. Benhen and Klee modified the Rosenmund-Kuhnhenn Method so that only one minute reaction time was required [2].Mukherjee,S.(1955) investigated and developed a rapid 
method for the estimation of unsaturation of fats and oils by use of an aqueous solution of sodium hypochlorous acid reagent as a absorption reagent with a reaction time of 4 to 5 minutes was recommend, the estimations are more rapid or all drying or non drying group oils give accurate results within the specified time [9].

Shin-ichiKikuno et al (1975) investigated the methods of quick determination of iodine value especially for the oil in the hydrogenation process and have found after all the Wijs method could be appropriate by only shortening the reaction time to three minutes for the oils of iodine value less than about 100. It also studied the effect of catalyst, temperature, time and I/CL ratio during the determination of iodine value [11].

Hashemy et al (1977) studied the IV of 121 samples of butter as well as some common oils and fats by applying both the standard and rapid Wij's and Hanus methods. In the rapid method a $2.5 \%$ of mercuric acetate in acetic acid was used. The result obtained are close and comparable for 1 min Wij's and 3 min Hanus methods as compared with 30 min reaction time of standard procedures [5].According to the united states patent (1981) when the magnesium acetate or sodium acetate is used in the form of a solution in glacial acetic acid, preferably having a concentration of 3-5 wt. \%. In this method; the reaction time of a sample with the Wij's solution is as short as short as about 3 minutes. Then, the iodine value is measured in the same manner as in the Wijs method. Since the analysis time is thus remarkably shortened [12].Lihua et al (1999) investigated a fast method for determining the IV of oils and fats using mercuric acetate without changing the operational steps of the Hanus method and reduced time from 30 minutes to 3 minutes. The experimental result indicates that fast method gives a variation coefficient is $0.31 \%$ [8].Zhongguo-ging (2004) investigated a new method for the determining the IV of oil and fat was only requires to add catalyst mercuric acetate in the process of determination without changing the operational procedure of Hanus method to reduce the reaction time of 30 minutes to 4 minutes. The experimental results indicate that the relative error is lower than $0.5 \%$ and coefficient of variation is lower than $0.2 \%$ [14].According to Yang Li,Ji Dong-bing et al (2014) investigated the improved determination method was tested by adding Wijs reagent and $10 \mathrm{ml} 3 \%$ magnesium acetate solution as catalyst reacting for $13 \mathrm{~min}$., Acc. The result showed that there was no great difference between 2 methods with relative error less than $2 \%$. It indicated that catalyst magnesium acetate had no adverse effect on accuracy of determination results [13].

\section{MATERIAL AND METHODS}

\subsection{Procurement of Materials}

Vegetable oils such as Kacchighani mustard oil (Kgmu, Dalda), Kacchighani mustard oil (Kgmu1, Mahakosh), refined mustard oil (Rmu, Tez), premium mustard oil kacchighaani (Pmukg, RRO Mustdil), Kacchighani mustard oil (Rmu, Nature fresh) and Kacchighani mustard oil (Rmu1,Engine) oils have been purchased from the local market and used in the present study for the determination of iv analysis. All these oils were in different forms of packaging while some in poly packs (HDPE), others were in tetra packs, plastic bottles, cans, pet and glass bottles of 1 litre and 5 litres. Since these eight different brands of edible oils were easily available for procurement (Table 1). Most of the brands have mentioned nutritional values, green vegetarian logo and best before 6 and 9 months, free from argemone oils on their packs. These different cooking oils are used in the present study for the determination of IV analysis.All the chemicals and reagents used in present experimental methodology are analytical grades.

\begin{tabular}{|c|c|c|c|c|}
\hline Sr. no & Name of oils & Brand & Place of manufacturer company & Product type/expiry* \\
\hline 1 & $\begin{array}{l}\text { Kacchighani mustard } \\
\text { oil }\end{array}$ & Dalda & $\begin{array}{l}\text { Vinayak Brother, Kachhwa Rd,Banaras } \\
\text { Allahabad Rd,Varanasi,UP-221313 }\end{array}$ & $\begin{array}{l}\text { High pungency, Zero Cholesterol, } \\
\text { Richest source of OMG-3 }\end{array}$ \\
\hline 2 & $\begin{array}{l}\text { Kacchighani mustard } \\
\text { oil }\end{array}$ & Mahakosh & $\begin{array}{c}\text { Jain Agro oils A-45,Matila } \\
\text { Village,Uttam nagar,New Delhi -110059 }\end{array}$ & $\begin{array}{c}\text { Contains Vit A and D,Pufa,low } \\
\text { Cholesterol }\end{array}$ \\
\hline 3 & $\begin{array}{l}\text { Kacchighani mustard } \\
\text { oil }\end{array}$ & Tez & $\begin{array}{l}\text { Recon oil Industries private } \\
\text { limited,Andheri East,Mumbai }\end{array}$ & $100 \%$ pure and natural \\
\hline 4 & $\begin{array}{l}\text { Premium mustard } \\
\text { kacchighaani }\end{array}$ & $\begin{array}{c}\text { RRO } \\
\text { Mustdil }\end{array}$ & $\begin{array}{l}\text { R R Oomerbhoy private limited ,soona } \\
\text { mahal,Mumbai }\end{array}$ & $\begin{array}{l}\text { Cold pressured, no cholesterol, no } \\
\text { trans fat }\end{array}$ \\
\hline 5 & $\begin{array}{l}\text { Kacchighani mustard } \\
\text { oil }\end{array}$ & Nature fresh & $\begin{array}{c}\text { Avent Agro PVT. LTD.1818 DISIC } \\
\text { Industrial cpmplex Narela,Delhi-110040 }\end{array}$ & Cold press extraction process \\
\hline 6 & $\begin{array}{l}\text { Kacchighani mustard } \\
\text { oil }\end{array}$ & Engine & $\begin{array}{l}\text { Shree Hari Industries, RIICO Industrial } \\
\text { Area,Bharatpur. }\end{array}$ & $\begin{array}{l}\text { Cold pressured, Agmark grade } \\
1,100 \% \text { pure Mustard oil }\end{array}$ \\
\hline
\end{tabular}

Table 1:- Different oils purchased from local market of Jalgaon city

*All the oils have best before within 6 and 9 months from the packaging. 


\subsection{Methods}

\subsubsection{Experimental Methodology}

In the present work, an attempt has been made to reduce the time of the Wijs method by use of mercuric acetate as a catalyst/accelerator. It provides a rapid method for the measurement of iodine value, wherein mercuric acetate is directly used in the powder form. The methodology includes addition of Wijs solution to a sample in an ordinary manner and then a powder form of the catalyst is added.The iodine value for a sample is determined in three set of experiments with $2 \mathrm{mg}, 5 \mathrm{mg}$ and $10 \mathrm{mg}$ of mercuric acetate as a catalyst. The sample is allowed to react with the Wijs solution for reaction time about 3 minutes and then the iodine value is measured in the same manner as in the Wijs method.

\subsubsection{Experimental procedure for determination of IV is according to Wijs method $[3,4]$.}

The only variation is the use of mercuric acetate as a catalyst to reduce the analysis time. To a $500 \mathrm{ml}$ conical flask with glass topper was weighed accurately an appropriate quantity of the dry oil/fat as per expected value $(0.2-0.22 \mathrm{mg})$,to which $25 \mathrm{ml}$ of carbon tetrachloride have been added and agitated for proper mixing. To this was added $25 \mathrm{ml}$ Wijs reagent and mercuric acetate. The sample was evaluated in three set of experiments with $2 \mathrm{mg}$, $5 \mathrm{mg}$, and $10 \mathrm{mg}$ of mercuric acetate as catalyst. The flask was fitted with glass stopper wetted with KI solution, swirled for proper mixing and kept in a dark for about 3 minutes for reaction. The test was also performed in absence of mercuric acetate where it was kept in darks for 30 minutes. Simultaneously a blank test was also performed. At the end of reaction, to the flask was added $15 \mathrm{ml} \mathrm{KI}$ solution followed by $100 \mathrm{ml}$ freshly boiled and cooled water with rinsing of the stopper. Liberated iodine was titrated with standardised sodium thiosulphate solution $(0.0998 \mathrm{~N})$ using starch as indicator until the blue colour formed disappears after through shaking. The iodine value was determined as follows:

Iodine value $=12.69 *(\mathrm{~B}-\mathrm{S}) *$ Normality of $\mathrm{Na}_{2} \mathrm{~S}_{2} \mathrm{O}_{3} /$ Weight of Sample taken

Table 2 reports the iodine value of different vegetable oils determined by regular Wijs method and by the catalytic Wijs method with use of $2 \mathrm{mg}, 5 \mathrm{mg}$ and $10 \mathrm{mg}$ mercuric acetate.

\begin{tabular}{|c|c|c|c|c|c|c|c|c|c|}
\hline \multirow[t]{5}{*}{ Sr. No } & \multirow[t]{5}{*}{ Oil/fats/Code } & \multirow[t]{4}{*}{$\begin{array}{l}\text { Expected } \\
\text { IV }\end{array}$} & $\begin{array}{c}\text { Use no } \\
\text { catalyst }\end{array}$ & \multirow{2}{*}{\multicolumn{3}{|c|}{ Use the catalyst }} & \multirow{2}{*}{\multicolumn{3}{|c|}{$\begin{array}{c}\% \text { Variation between catalytic and } \\
\text { non-catalytic Method }\end{array}$}} \\
\hline & & & \multirow{3}{*}{$\begin{array}{l}\text { catalyst } \\
30 \text { min. }\end{array}$} & & & & & & \\
\hline & & & & & $3 \mathrm{~min}$ & & \multirow[b]{2}{*}{$2 \mathrm{mg}$} & \multirow[b]{2}{*}{$5 \mathrm{mg}$} & \multirow[b]{2}{*}{$10 \mathrm{mg}$} \\
\hline & & & & (2mg) & (5mg) & (10mg) & & & \\
\hline & & (a) & (b) & (c) & (d) & (e) & $\begin{array}{c}(\mathbf{b}-\mathbf{c}) \\
* 100 / \mathbf{b}\end{array}$ & $\begin{array}{l}(b-d) \\
* 100 / b\end{array}$ & $(b-e) * 100 / b$ \\
\hline 1 & Kgmu & $96-112$ & 105.06 & 102.24 & 104.22 & 105.14 & 7.74 & 5.86 & 4.98 \\
\hline 2 & Kgmu1 & $96-112$ & 106.84 & 101.87 & 103.18 & 105.94 & 7.67 & 6.42 & 3.79 \\
\hline 3 & Kgmu2 & $96-112$ & 105.34 & 100.98 & 102.76 & 104.12 & 7.56 & 5.85 & 4.55 \\
\hline 4 & PmuKg & $96-112$ & 104.87 & 99.34 & 100.86 & 103.14 & 10.14 & 8.69 & 6.52 \\
\hline 5 & Kgmu3 & $96-112$ & 104.21 & 100.26 & 102.54 & 104.02 & 7.44 & 5.25 & 3.82 \\
\hline 6 & Kgmu4 & $96-112$ & 105.02 & 101.23 & 103.11 & 104.12 & 6.70 & 4.89 & 3.92 \\
\hline
\end{tabular}

Table 2:- IV Analysis of IV of vegetable oils by non-catalytic and catalytic Wijs method with reaction time of 30 and 3 min

\begin{tabular}{|c|c|c|c|c|c|}
\hline \multirow{2}{*}{ Sr. No } & \multirow{2}{*}{ iil/fats } & \multicolumn{3}{|c|}{ Use the Catalyst } & Use no Catalyst \\
\cline { 3 - 6 } & & IV $(2 \mathrm{mg})$ & IV $(5 \mathrm{mg})$ & IV $(10 \mathrm{mg})$ & IV \\
\hline $\mathbf{1}$ & Kgmu & 102.24 & 104.22 & 105.14 & 105.06 \\
\hline $\mathbf{2}$ & Kgmu1 & 101.87 & 103.18 & 105.94 & 106.84 \\
\hline $\mathbf{3}$ & Kgmu2 & 100.98 & 102.76 & 104.12 & 105.34 \\
\hline $\mathbf{4}$ & PmuKg & 99.34 & 100.86 & 103.14 & 104.87 \\
\hline $\mathbf{5}$ & Kgmu3 & 100.26 & 102.54 & 104.02 & 104.21 \\
\hline $\mathbf{6}$ & Kgmu4 & 101.23 & 103.11 & 104.12 & 105.02 \\
\hline $\mathbf{7}$ & Total & 605.92 & 616.67 & 626.48 & 631.34 \\
\hline $\mathbf{8}$ & Mean & 100.99 & 102.78 & 104.41 & 105.22 \\
\hline $\mathbf{9}$ & SD & 0.14 & 0.27 & 0.31 & 0.37 \\
\hline $\mathbf{1 0}$ & CV & 0.14 & 0.26 & 0.3 & 0.35 \\
\hline $\mathbf{1 1}$ & SEM & 0.08 & 0.16 & 0.18 & 0.21 \\
\hline
\end{tabular}

Table-3:- Accuracy of Iodine value in use of the catalyst and no catalyst

Mean values \pm SEM-standard error mean, SD-standard deviation, CV-coefficient of variation, IV-Iodine value 


\section{STATISTICAL ANALYSIS}

The data obtained from the experimental measurements and accuracy of IV for different Groundnut seeds oils have been analysed and the Statistical parameter like standard deviation and coefficient of variation were calculated for IV.All the experiment was carried out in triplicateand the results are presented as the mean SD,CV and SEM. Accuracy of descriptive Statistics of different groundnut oils from different parts of India as shown in figure1to 3.

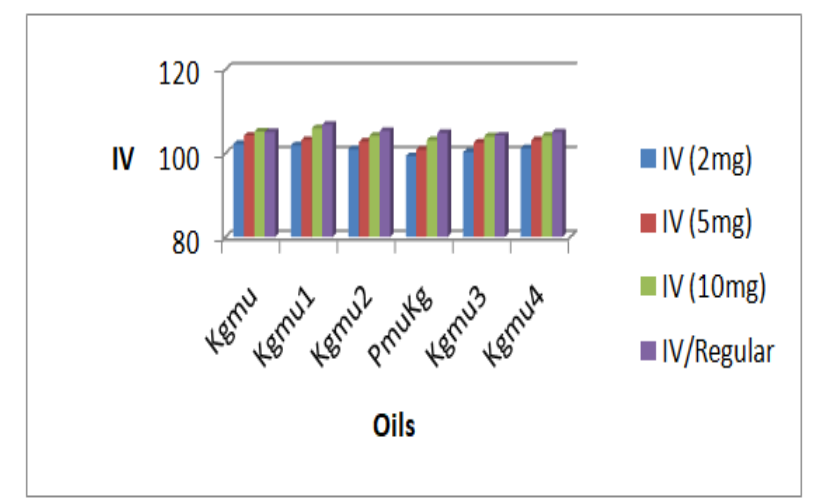

Fig 1:- Shows comparison of IV between reaction time of $30 \mathrm{~min}$ (Regular) and $3 \mathrm{~min}$ using $2 \mathrm{mg}, 5 \mathrm{mg}$ and $10 \mathrm{mg}$ mercuric acetate catalyst

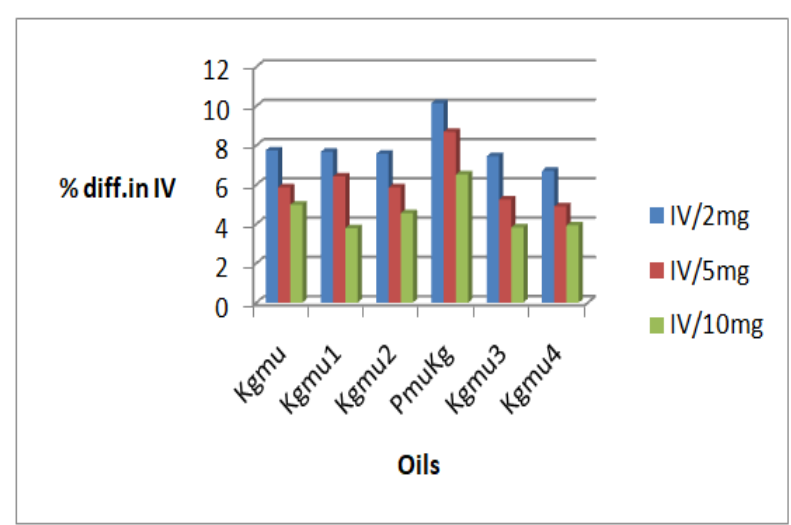

Fig 2 Shows comparison between $\%$ difference in catalytic and non catalytic IV in $3 \mathrm{~min}$ using 2,5 and $10 \mathrm{mg}$ of mercuric acetate

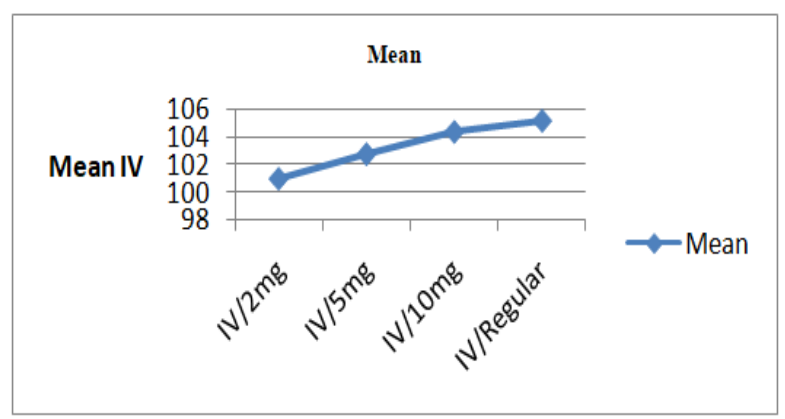

Fig 3:- shows the accuracy of descriptive statistics of different brands of groundnut oils in India.

\section{RESULTS AND DISCUSSIONS}

It is apparent from the Table 1.1that the iodine value for oil/fat obtained by the Wijs method and by the experimental method (modified Wijs method) is not significantly different. All the experimental values are average of five readings with good reproducibility of results. Also results obtained by use of mercuric acetate lies within the expected range, as per Food safety and standards act 2006 and Food product and Standards regulation 2011 [column (a) of Table] [4], of iodine value for respective oil/fat. The presence of catalyst has facilitated the increased reaction rate with reduction in time of analysis. It is observed that with increase in the quantity of catalyst reduces the difference in iodine value obtained by regular Wijs method and modified Wijs method. Accordingly use of $10 \mathrm{mg}$ of mercuric acetate gives least variation in the values obtained for all the studied oil samples. Comparatively more difference is noted in case iodine value by Wijs method and modified Wijs method for premium kacchighani mustard oil (Pkgmu)and Kacchighani mustard oil (Kgmu), wherein the allowed time of 3 minutes is not sufficient for reaction between iodine monochloride and pure kacchighani mustard oil and refined mustard oil. This has however reduced with the increase of catalyst quantity. Higher time of reaction may favour the reduction in difference in values of IV by regular Wijs method and modified Wijs method. The obtained value of IV for all studied samples by modified Wijs method represents the success of mercuric acetate to perform as catalyst in reducing the time of analysis to 3 minutes. Moreover, as all the reported values are average of three readings, has demonstrated the reproducibility of the analysis data. Table 1.2 shows the variance of the measured values of the method of setting it to 3 minutes. The coefficient of variation in case of $2 \mathrm{mg}$ is 0.14 while in case of $5 \mathrm{mg}$ (catalyst addition) 0.26 and in $10 \mathrm{mg}, 0.3$, even for non catalyst addition, 0.35 .

\section{CONCLUSION}

Present research examines the comparison between catalytic or accelerated method with original or noncatalytic Wijs method for IV analysis. The \% variation difference from 30 minutes IV ,It is found that there is more significant difference in case of $2 \mathrm{mg}$ and it is found that it is decreases with $5 \mathrm{mg} \& 10 \mathrm{mg}$ IV obtained by this catalytic method and standard AOAC method. Thus as a result catalytic Wijs method can be adopted as online quality control technique for rapid analysis during hydrogenation of oils and fats. The use of $10 \mathrm{mg}$ of mercuric acetate gives least variation in the values obtained for all the studied oil samples. The improved method, possessing good accuracy and reliability, is a rapid method for determination of iodine value in edible oil. 


\section{REFERENCES}

[1]. AOAC (2000), Association of official Analytical chemists, $17^{\text {th }}$ edition, Official Method 920.159-Iodine absorption number of oils and Fats/ISI Handbook of food analysis(part XIII)1984,76.

[2]. Benhem et al (1950), Benhem,G.H., and Kell,L.1950,An improved method for the determination of iodine number. Journal of American Oil Chemists Soc. 27:127-129.

[3]. DGHS (2012), Directorate of General Health Service, Manual of Methods of Test and Analysis for Food(Oil and Fats),Ministry of Health and family welfare, Government of India, New Delhi.31-34.

[4]. FSSA 2006 (2014), Food Safety and Standards Act 2006, Rules 2008, Regulations of food Product and Standards 2011, $8^{\text {th }}$ edition professional book publishers, New Delhi.

[5]. Hashemy et al (1977), S.E.Hashemy-Tonkabony, Rapid lodine value determination using mercuric acetate as accelerator .,journal of American oil chemists society, 54(6), 233.

[6]. Hoffman et al (1939), Hoffman,H.D, and Green,C.E.,1939,A rapid method for the determination of iodine number, oil and soap, 16:236-38.

[7]. Jnmiat et al (1916), JnmiatVishindasLaMani and John Joseph Sudborough, The determination of the Iodine values of Fats and Oils by Winkler's Bromate Method.,173-177.

[8]. LI Hua et al(1999),LI Hua,EniwerArboundrar, AhemeityManlihar.,A fast determination method of IV of oil and Fat, Journal of Xuzhou Normal University ,Fine Chemicals, 03.

[9]. Mukherjee,S.(1955), A rapid method for estimating unsaturation of Fats and oils by the use of hypochlorous acid reagent. Journal of American Oil Chemists Soc. 32,351-353.

[10]. Samara et al,(2018),Samara Soares,Fábio R. P. Rocha,Fast Spectrophotometric Determination of Iodine Value in Biodiesel and Vegetable Oils,Journal of Brazilian chemical society,vol.29(08),

[11]. Shin-ichiKikuno et al (1975),ShinichiKikuno, YukinobuMurase, ShoujiMaruzeni and Minoru, On the Determination of Iodine Value by the Wijs Method, Okamoto.Journal of Japan Oil Chemists Society, 24(12),876-878.

[12]. US Patent 4297106 (1981), United States Patent ,Rapid method of the measurement of Iodine Value (11)4, 297,106, Makino, (45).

[13]. Yang Li et al(2014), Yang Li,Ji Dong-bingXuedunhui, ChenRong, Du Hong-ying, Lu Wet-tong., A rapid method for the determination of edible oil iodine value, Journal of Science and Technology of cereals, oils and Foods, (02).

[14]. Zhongguo-ging(2004), A rapid method for the determination of iodine number, Journal of science and Technology of cereals, oils and Foods,(01). 